\title{
QUALITY and EFFICACY of the INDIGENOUS TUTORIAL ASSISTANCE SCHEME (ITAS) for UNIVERSITY STUDENTS
}

SUE WHATMAN, JULIANA MCLAUGHLIN, SUSAN WILLSTEED, ANNIE TYHUIS, \& SUSAN BEETSON

Oodgeroo Unit, Queensland University of Technology, Kelvin Grove, Queensland, 4059, Australia

Abstract

Designed as a "supplementary" tuition scheme, the Indigenous Tutorial Assistance Scheme (hereafter referred to as ITAS) is a strategic initiative of the National Indigenous Education Policy (DEET, 1989). This paper seeks to contribute to the literature of the analysis of the quality and efficacy of ITAS. Currently, the delivery of ITAS to Indigenous students requires enormous administration and commitment by the staff of Indigenous education support centres. In exploring the essential but problematic provision of ITAS to Indigenous university students, this paper provides insights into significant aspects of our program that move beyond assumptions of student deficit, by researching the quality of teaching and learning through ITAS, analysing administrative workload, and sharing innovations to our program as a result of participatory research with important ITAS stakeholders.

\section{Introduction}

The Indigenous Tutorial Assistance Scheme (ITAS), a nationally funded program through the Department of Education, Employment and Workplace Relations (DEEWR), has been conceptualised and implemented upon a number of premises, including that Aboriginal and Torres Strait Islander students have had a "deficient" preparation in their schooling to "successfully" undertake tertiary study. This claim is drawn from many reviews and analyses of Indigenous education support initiatives and national Indigenous education policy (Bin-Sallik, 1991; Morgan, 2003; Nakata, 1993, 2001; Nicholls et al., 1996; Taylor, 2002; Tripcony, 2001). This paper analyses ITAS by interrogating concepts informing perceptions of "deficit" and "success". Herbert's (2005) work on Indigenous tertiary students' success was used in this analysis.

By reviewing the history of the development of ITAS at the Queensland University of Technology (QUT), we aim to demonstrate how national educational policy foundations (and assumptions about teaching and learning with Indigenous students) have affected the development of the ITAS program. We want to pay specific attention to the quality of tuition and the administrative workload associated with the provision of ITAS to university students. It is our contention that conceptual problems with ITAS adversely affect the administrative load of delivering the program, mostly borne by Indigenous staff in centres such as ours. We conclude the paper by drawing attention to innovations to our own ITAS program. Our program attempts to address conceptual problems underpinning Indigenous student support through ITAS, with a view to greatly improve the quality of teaching and learning, and reducing the administrative burden of the ITAS program.

Indigenous student support strategies and notions of "deficit"

ITAS for Indigenous students is a strategic Commonwealth Government-funded initiative of the National Aboriginal and Torres Strait Islander Education Policy (NATSIEP). Following on from the years of lobbying by groups such as the National 
Aboriginal Education Committee throughout the 1970s (Tripcony, 2001; Watts, 1982), and the various reviews and recommendations by groups such as the Aboriginal Education Policy Task Force, the Department of Employment, Education and Training (DEET) developed the first National Aboriginal Education Policy (DEET, 1989). The policy was developed in consultation with various Aboriginal and Torres Strait Islander individuals and organisations. The specific long-term goals are:

- to involve Indigenous people in decisions about their own education, and actually deliver educational services;

- to provide equal access to all levels of education, from pre-school to tertiary, on par with the rest of the population;

- for Indigenous people to take part in all levels of education, in a relevant and enjoyable way, to the same extent as other Australians;

- for fair educational results of Indigenous people in terms of their own performance, and the appreciation by all Australians of their history and culture (DEET, 1989, p. 3).

The policy has been implemented through a variety of strategic, federally-funded initiatives including Homework Centres for schools, Vocational Education funding, the Indigenous Educational Strategic Initiatives Program (IESIP) and the provision of the Indigenous Tutorial Assistance Scheme through Indigenous Education Direct Assistance (IEDA) funding (Mellor \& Corrigan, 2004). The reporting and accountability frameworks which accompany each initiative are framed around the long-term goals and the assumptions upon which these goals are based.

Indigenous scholars such as Nakata (1993, 2001) and Tripcony (2001) critiqued some of the assumptions underpinning the national policy. The emphasis upon Indigenous identity and the need for "culturally appropriate" education is seen by Nakata (2001) as both the source of the "problem" and the "answer" for addressing educational underachievement and as such is an unresolved paradox. Mainstream schooling practices are not problematised at all as affecting Indigenous educational achievement, and thus curriculum reform and the positioning of Indigenous people "vis-à-vis colonial knowledges and practices remains unchallenged" (Nakata, 2001, p. 344). While national policy describes Indigenous students as the "most disadvantaged" as the explanation for (lack of) educational success, Tripcony (2001) argued that the system which positions them there cannot be challenged or changed. Hence, the support mechanisms developed around these assumptions are also difficult to change. Attempts to offer appropriate educational strategies for Indigenous learners often have been premised upon what it is that they "lack", with such strategies being envisaged as compensatory (Nakata, 2001, p. 341).

Research into Indigenous student educational success has broadened over the last decade to focus upon systemic problems and curriculum reform (Nicholls et al., 1996; Phillips, 2005). However, Harrison's (2005) research reminds us that "deficit models" in explaining Indigenous educational success are still firmly entrenched in the academy:

It is often assumed in education that we have left the deficit model behind, but ... policies and programs continue to position Indigenous students within a discourse of progress and enlightenment. Through this discourse, they are positioned between an image of what they once were as disadvantaged and what they are supposed to become in the process of studying at school and university ... messages ... are secretly transmitted both inside and outside the classroom when Indigenous students are constituted in discourse as "behind" or "below" and having to "catch-up" to the non-Indigenous students (Harrison, 2005, p. 41).

Variations in Indigenous students' successful learning, particularly towards the acknowledgement of students' prior knowledge and how this contributes to their "success" at university has been identified by Boulton-Lewis et al. (2000) and Herbert (2003). Prior knowledge may evolve from family sources (students who have had relatives studying before them), exposure to university expectations through other schooling avenues and the student's own work and learning journey prior to formal study. Sourcing personal stories from Indigenous students to elicit prior knowledge as an indicator of success is paramount (Herbert, 2003, p. 2). Herbert argued for a concerted effort to incorporate the Indigenous student voice in any discussion about "success":

It has not been the Indigenous voice that has directed their positioning in Australia's educational institutions ... I sought to open up a space in which Indigenous Australian respondents might speak back to non-Indigenous educators, thus becoming a part of the process that is needed to change the discourse about Indigenous Australian student achievement in higher education (Herbert, 2003, p. 2).

Herbert (2003) echoes the position taken by Nakata (1999, 2001), Rigney (1997) and Smith (1999) speaking back to the academy about its positioning of Indigenous scholars and Indigenous students. She argues for a change in discourses around Indigenous tertiary educational achievement as "deficit" in order to allow for greater recognition of, and ability to 
define, Indigenous success. A new discourse would recognise that respect for Indigenous knowledges in the academy is essential for student empowerment and success (Herbert, 2005, pp. 19-22).

Indigenous scholars around Australia have recently argued for the value of Indigenous knowledge in the academy to be recognised. This is evident through the release of the Indigenous Knowledge Statement by the Indigenous Higher Education Advisory Council (IHEAC, 2006). Priority Four of the Statement, to "improve the rates of success, retention and completion for Indigenous students" (IHEAC, 2006, p. 20) argues for careful attention to be paid to processes that "appropriately prepare" students to successfully complete their studies, which is the primary focus of ITAS programs at universities. As "cultural alienation" at university contributes to non-completion (IHEAC, 2006, p. 20), we wanted to explore the potential for ITAS to include a form of knowledge exchange between students, tutors and the wider university. It is hoped this will inspire curriculum reform and better tutoring practices, reducing the incidence of such alienation and its dire consequences for Indigenous students. Accordingly, we hope to contribute to an identified area of need, with IHEAC (2006, p. 23) calling for a "national review of the relationships between Indigenous support initiatives and Indigenous Education and Support Centres" including the development of Indigenous knowledge and pedagogical approaches in university curricula.

The final issue that has clear implications for the quality of teaching and learning through ITAS at our university is the fact that the medium of instruction in Australian universities is Standard Australian English (SAE), and for many Indigenous students at QUT, SAE is at least their second language. We have a high proportion of ITAS users (12\%) who are Torres Strait Islanders and for whom SAE is in fact their third or fourth language (Shnukal, 2002, p. 8). Taylor's (2002) research into national and State educational policy responses through her work with the Indigenous Education Training Alliance (IETA) in Cairns demonstrated that State education departments acknowledged the responsibility of schools to respond to Indigenous students' English as Second Language (ESL) needs with "second language pedagogy" (p. 45). However, universities are not required to do so for Indigenous students. Whilst individual universities may make allowances for Indigenous students to have additional exam time or use English dictionaries, similar to International ESL students (see http://www.studentservices.qut.edu.au/ assess/exams/nesb/allowances.jsp), DEST guidelines will only allow ITAS funding to target ESL needs under exceptional circumstances. As such, the teaching and learning needs of Indigenous students who are ESL, and subsequent second language pedagogies, remain in constant tension with the objectives of university - delivered ITAS programs.
As ITAS is intended to contribute to improved student outcomes, we argue that a critique of "student outcomes" is necessary. This should include problematising "the deficit model" of explaining student success or lack thereof, defining success in the context of Indigenous tertiary education, recognising students' prior knowledge and exposure to university, and identifying how much say they have in their educational experiences. Further, there is the need for embedding Indigenous knowledge in universities programs. The impact of ESL status among a significant proportion of Indigenous students and their subsequent achievement should be recognised.

The research project

The context of ITAS at QUT

Centralised administration of the Aboriginal Tutorial Assistance Scheme (ATAS - hereafter referred to as ITAS) at QUT began in 1990, after the former Brisbane College of Advanced Education (BCAE) merged with the Queensland Institute of Technology (QIT). Currently, ITAS is administered by the Oodgeroo Unit, which is the university's Aboriginal and Torres Strait Islander centre for teaching, research, student support and community service (see www.oodgeroo.qut.edu.au).

The improvement in rates of student participation and perception of "success" were directly linked, as increased student completions tied to ITAS led to an increase in the amount of funding that education providers would be entitled to in future years. Funding was not specifically tied to "proving" the quality of the program; that was implied by increasing numbers of graduates. However, our experience at QUT indicates that there are numerous variables affecting the access, participation and graduation rates of students, including but not limited to:

perceptions of financial support available to potential students; university cut-off scores; university "inducements" that differ from each institution; reputation (especially amongst alumni); history of family enrolment; physical location of the institution (McLaughlin, 2006, p. 21).

Policy changes in other student related areas such as eligibility criteria for Abstudy and Youth Allowance may also affect the number of Indigenous students applying for tertiary study or increase pressure on students who must supplement their income through part-time work. These students may experience difficulty in managing academic workloads and family/ employment commitments which thus impact directly on student completions (Oodgeroo Unit, 2003).

With the emphasis on statistical reporting, there is no requirement or incentive for education providers 
to research the impact of such variables, nor the quality of teaching offered through ITAS. The issue of academic excellence was also overlooked by the focus on numbers of graduates. The burden of "proof" was limited by national policy to only reporting changes in student outcomes. For example, when the Indigenous Education (Targeted Assistance) Bill 2000 was introduced to replace the previous Supplementary Assistance Act (1989), the new reporting requirements of this Bill remained concerned solely with the number of students accessing the funded programs, the number of education providers accessing program funding, and the total cost of such programs by State and provider (DEST, 2002). This confirmed our observation that education providers of ITAS were not required to examine the quality of teaching and learning of their program in order to satisfy their auditing/reporting obligations.

With full responsibility for ITAS at QUT, the Oodgeroo Unit made the decision to fund a full time ITAS Administrator out of its own recurrent funding (Oodgeroo Unit, 2000). Oodgeroo Unit academic staff members were now required to:

- conduct educational assessments,

- approve applications for ITAS assistance on the basis of the educational needs assessment,

- interview and recommend tutors for appointment,

- allocate tutors to students,

- conduct cultural awareness sessions,

- approve work programs, and review progress and tuition assessment.

\section{Professional staff:}

- maintain the tutor and student databases,

- review and revise standard forms,

- revise information kits for tutors, students and academic staff,

- confirm tutorial arrangements in writing,

- check and approve tutor claim forms and timesheets,

- monitor salary and non-salary expenditure,

- coordinate cultural awareness sessions,

- maintain student and tutor files,

- prepare the Funding Grant for external audit and various mid and end of year financial and program reports.

ITAS funding guidelines were amended with the introduction of the Indigenous Education (Targeted Assistance) Amendment Bill 2004. The major differences in reporting requirements included ITAS student results, information about the effectiveness of different tutoring strategies, such as group versus individual tuition, and information about changes to student behaviour and attitudes (for example, the number of "no shows" that any student has for a booked tutorial session). Statistical data to satisfy the new requirements was already available with existing reporting mechanisms, specifically the student/result table, and student/tutor table. However, reasons behind any changes in behaviour were not required by DEST, even though such data are captured through qualitative student evaluations of tutors, and tutor final progress reports. With limited feedback from DEST (Oodgeroo Unit, 2003) as to the value of information provided to them, and the absence of constructive feedback on ways to improve the quality of ITAS, Commonwealth guidance on improving our program remained minimal.

In 2004, the Oodgeroo Unit made a significant change to ITAS access for students and tutors by making most of the administrative paperwork available online through the Oodgeroo Unit website (see www.oodgeroo.qut.edu.au). This was one response to the acknowledgement made in the 2003 review that part time, postgraduate and externally enrolled students did not have day time access to academic staff who would normally provide it, and this was having an impact on their uptake of ITAS support. ITAS at QUT is currently used by approximately $25 \%$ of Indigenous students (95 students out of 380, see Table 1). 12\% of ITAS applicants are ESL students from far North Queensland and the Torres Strait. QUT is performing well nationally and within Queensland for student enrolments (access) and participation. Whilst QUT's overall performance in enrolling (recruiting) students decreased marginally between 2003 and 2004, participation (continuing students) increased, suggesting effective student support mechanisms operating within the Oodgeroo Unit, including ITAS (Oodgeroo Unit, 2005).

Aboriginal and Torres Strait Islander students offered a place through the QUT alternative entry program are advised and assisted to apply for ITAS. An invitation is sent to all enrolled Indigenous QUT students when classes commence. As shown in Table 1 below, the uptake of ITAS by students across each faculty varies from $2 \%$ for postgraduate students (for whom access to ITAS is restricted by federal guidelines) to $38 \%$ for Creative Industries and Health students. Whilst Education and Creative Industries faculties show a higher uptake in the first year, Law and Health faculties have a consistent usage rate over the four years.

Our enrolment figures and success rates are slightly better than the national average (Oodgeroo Unit, 2005), but our ITAS participation rates in some faculties are quite low (2\%-8\% for example). Given our above discussion that ITAS reporting requirements do not illuminate quality teaching and learning practices, it is crucial that we identify and assess the quality of effective student support against national trends of decreasing Indigenous participation in university education.

The emerging interest in the quality of teaching and learning in ITAS is related to broader developments outside of the Oodgeroo Unit. Firstly, it correlates with the University's teaching and learning 
commitments in the QUT Reconciliation Statement (see www.reconciliation.qut.edu.au). Additionally, the Education, Law, Creative Industries, Carseldine School of Humanities and Human Services and Health faculties through the provision of the Teaching and Learning Grants Scheme, undertook projects which concentrated on Embedding Indigenous Perspectives in the Curriculum (Carpenter et al., 2002; Macpherson \& Aspland, 2000; Nash, 2004; Williamson \& Dalal, 2007; Williamson \& Towers, 2004).

From 2003, the Faculty of Education, in consultation with the Oodgeroo Unit, introduced an Indigenous Education unit as one of its core units. An Oodgeroo Unit academic was seconded to conceptualise, develop and co-ordinate this unit, which was the first compulsory Indigenous studies unit for pre-service teachers in Queensland. An associated development was the publication of the textbook, Introductory Indigenous studies in education: The importance of Knowing, (Phillips \& Lampert, 2005), with chapters contributed by most of the academic staff within the Oodgeroo Unit, to support teaching and learning in the core unit. These outcomes, and many more, are directly associated with embedding Indigenous perspectives in university curricula projects that we have identified as having an impact on the "success" of Indigenous students across QUT (McLaughlin \& Whatman, 2007).

\section{Research aims}

The research project was motivated by the need to gain a better profile and understanding of the quality of learning and teaching processes in ITAS. It was intended that this would provide an opportunity to do some quality control, better deliver ITAS to students already accessing this service, and market it to students who are not (up to $92 \%$ of students, in the case of Science, see Table 1). Engagement of students' attitudes and aspirations in learning (Herbert, 2003, 2005) was considered essential to understanding how ITAS could be better managed at QUT, to improve the quality of the tutoring experience for students and to lead to improved student results and retention rates.

Recruitment of quality ITAS tutors was a concern (Oodgeroo Unit, 2003). Student results at the end of semester and a low return rate of Student Evaluations of Tutors were the only means of gauging the quality of tuition which had occurred, with neither method eliciting rich data. Some preliminary conversations and activities were undertaken by a special ITAS project team and the research focus was refined. A new ITAS system was envisaged to capture teaching and learning processes that give a better insight into the quality practices of effective ITAS tutors, as well as provide feedback and opportunities for tutors to improve their practice. Hence the research aims of the project were:

1. How does the Oodgeroo Unit monitor and assess the quality of teaching through the ITAS program and how does the Unit use this information year to year?

2. What are the effects on the quality of teaching and learning through ITAS, and its administrative procedures as they relate to students, ITAS tutors, staff and the ITAS coordinator?

\section{Decolonising methodology}

This research study into both administrative and educational processes at QUT acknowledged the

Table 1. 2007 students accessing ITAS tutoring within the 0odgeroo Unit, QUT.

\begin{tabular}{|c|c|c|c|c|c|c|c|c|c|}
\hline Faculties & $\begin{array}{c}\text { No of } \\
\text { enrolled } \\
\text { students }\end{array}$ & $\begin{array}{c}\mathbf{Y r} \\
1\end{array}$ & $\begin{array}{l}\mathbf{Y} \mathbf{r} \\
2\end{array}$ & $\begin{array}{c}\mathbf{Y r} \\
3\end{array}$ & $\begin{array}{c}Y \mathbf{r} \\
4\end{array}$ & $\begin{array}{l}\text { Double } \\
\text { degree }\end{array}$ & $\begin{array}{l}\text { Post } \\
\text { Grad }\end{array}$ & $\begin{array}{l}\text { Total } \\
\text { ITAS } \\
\text { users }\end{array}$ & \% Use \\
\hline Education & 54 & 8 & 4 & 5 & 2 & & & 19 & $35 \%$ \\
\hline Creative Industries & 29 & 5 & 4 & 1 & 1 & & & 11 & $38 \%$ \\
\hline Health & 53 & 10 & 5 & 5 & 0 & & & 20 & $38 \%$ \\
\hline Law / Justice Studies & 57 & 4 & 5 & 5 & 0 & & & 13 & $23 \%$ \\
\hline $\begin{array}{l}\text { Built Environment } \\
\text { \& Engineering }\end{array}$ & 31 & 5 & 0 & 0 & 1 & & & 6 & $19 \%$ \\
\hline Science & 12 & 0 & 1 & 0 & 0 & & & 1 & $8 \%$ \\
\hline Business & 37 & 4 & 2 & 0 & 0 & & & 6 & $16 \%$ \\
\hline Information Technology & 15 & 2 & 1 & 0 & 0 & & & 3 & $20 \%$ \\
\hline $\begin{array}{l}\text { Humanities / Human } \\
\text { Services }\end{array}$ & 25 & 5 & 2 & 2 & 0 & & & 9 & $36 \%$ \\
\hline Double Degree & 23 & 0 & 0 & 0 & 0 & 6 & 0 & 6 & $26 \%$ \\
\hline Postgraduate & 44 & 0 & 0 & 0 & 0 & 0 & 1 & 1 & $2 \%$ \\
\hline TOTAL & 380 & 43 & 24 & 15 & 6 & 6 & 1 & 95 & $25 \%$ \\
\hline
\end{tabular}


struggles that exist within Australian university centres to decolonise Western knowledge. The researchers went into this study with an understanding of Indigenous knowledge and research ethics (AIATSIS, 2000; NHMRC, 2003). Indigenous research protocols, including respect and responsibility for participants, the ITAS scheme itself and the Oodgeroo Unit, informed the conceptualisation and development of the study. The research team acknowledged existing knowledge gained over years of experience in ITAS administrative tasks by both academic advisors and professional staff. Researchers recognised the responsibility that associates with the conceptualisation and conduct of research and the dissemination of its outcomes. This research team was highly aware that such "insider research" may challenge and unsettle beliefs, values and existing knowledge (Smith, 1999, p. 139) and we were prepared for different challenges to be thrown at the project by fellow colleagues, students and the university administrative personnel.

Indigenous scholars, such as Martin (2001) and Smith (1999) argue that decolonising methodologies are defined by interconnectedness and interrelatedness between people, knowledge and the natural world As such, the research process precedes objective measurement, and honours the primacy of direct experiences and cultural values (Walker, 2003). A sense of responsibility to the "researched" informs the conduct and methods of reporting the study. Rigney (1997, p. 118) classified Indigenous research as being informed by three fundamental and inter-related principles including resistance, political integrity and privileging Indigenous voices. While the first two principles inform this research through subtle ways, privileging Indigenous voices is fundamental to this study. This study focused upon past experiences, contemporary practices and aspirations of Indigenous educators and students. The research team was highly sensitive to ideas and practices of colonial hegemony (Rigney, 1997). Rigney argued that research conducted by Indigenous people is "Indigenist" research, and should achieve the privileging of Indigenous voices, political and lobbying agendas, and ultimately the emancipation of Indigenous peoples. We acknowledge other Indigenous and non-Indigenous scholars who have argued for respectful research with Indigenous peoples (Brady, 1992; Fredericks, 2007; Hart \& Whatman, 1998; Houston, 2007; Huggins, 1998; Moreton-Robinson, 2000, 2004; Stewart, 2007; WeberPillwax, 2001). There was an awareness of and respect for all participants.

This research project investigates ITAS provision in one location. The concentrated focus on one location will enable staff to constantly and critically reflect on their current practice, and develop innovative ideas for enhancing student support through ITAS. A case study methodology was deemed appropriate for such investigation. Understanding ITAS at QUT is of intrinsic interest (Stake, 1995) to us to improve internal processes, yet it is also instrumental (Bassey, 1999) in that we hope to influence broader policy impacting upon the delivery of ITAS.

Adhering to principles of Indigenous methodology, data collection strategies deemed appropriate and respectful for this research included workshops as a form of focus groups (see Smith, 1999; Stewart, 2007), document analysis, individual interviews, and qualitative survey. Focus groups were conducted with Indigenous and non-Indigenous staff, both academic and professional, between July 2006 and June 2007. A number of small groups were convened initially in 2006, leading to a whole staff focus group in November 2006. Findings of previous sessions were collated and returned to the staff for further input, clarification and/or rejection. A "wish list" was collated from every staff member outlining their hopes and expectations of ITAS in a virtual environment. In June 2007, we held the last focus group, presenting the prototypein-development of the ITAS virtual environment. Feedback from all staff in this session was captured in field notes to further inform the research project.

Documents consulted included meeting minutes from 2001 to 2007, Oodgeroo Unit Annual ATAS/ITAS reports to DEST, the Oodgeroo Unit Submission to the 2003 Review of Bulk Funding Arrangements, DEST policy documentation, QUT policy documents, and various government reports. The ITAS administrator, former ITAS coordinators, academic staff, professional staff, students and tutors participated in unstructured, informal interviews about ITAS between July 2006 and June 2007.

The aim of qualitative survey research is to describe characteristics of individuals, groups and/ or organisations, with broader aims of monitoring trends and testing theoretical understandings of social processes (LeCompte \& Preissle, 1993). Views of participants allowed the research team to identify key indicators of the quality of teaching and learning. Participants can be categorised into the following groups:

- Aboriginal and Torres Strait Islander students currently using or having previously used ITAS

- Aboriginal and Torres Strait Islander students who have chosen not to use ITAS, or are not using it for other reasons (such as tutor unavailability)

- ITAS tutors - current and past

- Current academic staff who appoint tutors

- Current professional staff who administer ITAS

All students and tutors were invited via email to complete a survey. Twenty-one students participated in the project representing 22\% of students actively involved in ITAS, and $5.5 \%$ of all Indigenous students enrolled at QUT. Twenty-one tutors participated in the project representing $30 \%$ of ITAS tutors. Academic 
and professional staff volunteered to attend two ITAS Workshops. All professional staff members were asked to complete an online survey. We also involved several key informants, with extensive knowledge of the history and administration of ITAS, including the Unit manager, previous ITAS coordinator and DEST representatives at State level.

Indigenous research ethics (AIATSIS, 2000; Donovan \& Spark, 1997; NHMRC, 2003) dictate that participants reserve the right to reveal or conceal their identity - indeed, to be able to control how their identity is constructed in the text (Hart \& Whatman, 1998). Confidentiality of participants identities was maintained at all stages of data analysis and presentation of findings. While readers who are knowledgeable of the case study site and its people may recognise individual identities through deduction or their existing relationships, the use of pseudonyms provides the confidentiality required to present the data to a wider audience.

\section{Presentation of preliminary findings}

The following discussions emerged from preliminary investigations into the experiences and perspectives of key stakeholders in the ITAS administration at our university.

\section{Burden of administration}

We investigated the current process of ITAS at the Oodgeroo Unit, which was a paper based records system. Staff surveys indicated that one of the biggest hurdle experienced is the handling of this paper work. Records of staff meetings minutes, particularly since 2000 , revealed that the administration of ITAS gradually became a permanent agenda item (see Beetson et al., 2007). A number of factors contributed to this increased focus on the administration of ITAS. For example, the administrative funding for ITAS within universities is directly capped at $15 \%$ of total funding by DEST, with any additional costs borne by the educational provider. The Oodgeroo Unit shares this administrative load across most of its staff. However, the changing nature of the work within the Australian academic community leaves staff in a dilemma under the current DEST administrative requirements. While student support continues to be a major responsibility for academic staff, promotional criteria focus on teaching, community engagement, research activities and consequent publications (IHEAC, 2006; QUT, 2007). Delegation of an enormous share of the ITAS administrative load to academic staff impacts on their chances of promotion and career advancement. Therefore, we argue that the difficulty of nurturing an academic career is increased, if staff time is consumed with administrative tasks rather than scholarly engagement.

\section{The deficiency model (academic inability)}

Our findings demonstrate that adhering to the requirements of DEST reinforces the notion that ITAS is called a "supplementary", but is devised as, a "compensatory" tuition program to address a perceived, nation-wide deficiency in Indigenous students' educational abilities (Nakata, 2001; Tripcony, 2001). While quantitative data about grades and numbers of applicants is collected to satisfy DEST requirements, it fails to adequately explain success and failure rates at individual institutions, academic and personal factors that contribute to learning difficulties, and the reasons why students decide not to apply for ITAS at all, yet successfully pass all their subjects. Reasons for refraining from using ITAS would provide some insights into students' academic abilities and may challenge the "deficient" perception of Indigenous students studying at universities. The current DEST reporting requirements do not adequately seek to understand these issues, yet it would yield greater insights into the factors affecting Indigenous student "success" at university level.

Tutoring guidelines and reporting requirements that focus only on pass/fail rates and the number of hours a student receives tuition do not address the quality of that tuition, the individual roles, nor expertise of tutors. It can be argued that passing of assessment tasks takes precedence over in-depth understanding of the subject content and study skills, particularly from the student's perspective. Survey responses from students and tutors indicate the concentration on assessment outcomes is a legitimate indicator of ITAS "success", but it can create tension between the students' and tutors' aspirations. For example:

Many tutors believe that just because they are tutoring you that you will receive a 6 or 7 . They seem disappointed that it's only a pass. I believe in aiming high and trying to be happy with what I get. However, I tend to feel like a failure when you know that a tutor thinks you will receive a higher mark than you receive (Student \# 8).

I have found with some students that they seem keen to use the tutoring sessions as a crutch for problematic assessment rather than as a forum for additional learning (Tutor \# 3).

It is, therefore, not surprising that the DEST administrative guidelines influence the mode of teaching and learning through the ITAS program, and the subsequent teaching and learning relationship that is established between the tutors and students over the semester. While education providers must adhere to regulations, many pedagogical and cultural issues which impact on student learning are ignored. What appears to be missing is a genuine and authentic assessment 
of the teaching and learning relationships facilitated by the ITAS program, from the people who matter most - the student recipients, their tutors, and the academic and professional staff who make it possible.

\section{Expectations of quality tuition}

In order to enhance the provision of ITAS and other student support services in our Unit, insights from students and tutors were essential. From 2005, Indigenous students applying through the alternative entry program have completed a survey which focused on their expectations of ITAS. Interpreting assignment topics and content knowledge, and research and academic writing skills were the most frequently requested kinds of academic support they would like to receive from their tutors. Specifically, this acknowledges the tutor's expert knowledge. Students undertaking technologically oriented course such as IT, engineering and environmental design also wanted the technological expertise of specific tutors:

More assistance with layout and problem solving (required) (ITAS Student \#19).

Understanding coding techniques (ITAS Student \#11).

Learning how to program and use databases (ITAS Student \# 13).

Helping me with my drawing subject - perspectives and layout design process (ITAS Student \#21).

Students indicated that assistance for examination and assessment preparation were highly valued, closely followed by cultural support, both in sharing academic experiences and in showing respect to students' Indigenous identity. Also relevant were the personal attributes of tutors such as friendliness, punctuality, and encouragement:

Taking time to discuss assignments first, listening to my perspective as an Aboriginal, being relaxed and approachable (ITAS Student \# 4).

Dedicated to the betterment of positive outcomes for Indigenous Australians, easy going and easy to relate to, expert in the field of study (ITAS Student \# 18).

Eagerness to assist, experts in the field, experience with study and ability to quickly pick up the content to answer any questions I may have had (ITAS Student \# 19).

One of the conclusions from our research is that the process for students requesting ITAS assistance needed to be more dynamic. This would accommodate changing priorities as they progress throughout their course, and allow scope to describe their teaching and learning concerns in more detailed ways. The template for a new, online application process was developed from this data (Beeston et al., 2007).

Expectations from past ITAS students (2004-2005), canvassed a range of issues, including the limit of two hours per subject per week, the appropriateness of tutors' qualifications and tutor availability:

I found that the two hours per week really just wasn't enough (greedy eh?!!) but we really needed four. Two for reading and writing and two for the coursework (Past ITAS Student E).

Subject is part of the faculty of Finance and Economics and the tutor who is a staff member of the Accountancy faculty had a tendency to teach the work from an accountancy point of view which at times made it difficult and confusing to understand (Past ITAS Student A).

Tuition was difficult to obtain and there was only a few weeks of tuition with tutor (Past ITAS Student D).

It was hard sometimes due to the fact that I needed to work on a couple of major projects for other subjects and didn't have enough time for this one (Past ITAS Student F).

Individual student needs may include ESL considerations when English is not their first language, as $12 \%$ of our ITAS cohort identifies as ESL speakers. Another key issue was the carrying over of ITAS hours from previous weeks, to be used when the students most require them (that is, around project dates). ITAS tuition hours cannot be stockpiled under current regulations.

\section{Discussion}

Several key issues emerged from this research project. These include inflexibility of DEST requirements, the quality of student - tutor relationships and the resources to support learning experiences.

\section{Inflexibility of DEST requirements}

The schedule of tuition is strictly guided by DEST guidelines. Inflexibility of ITAS tuition can overshadow the quality of learning. As noted previously, the observation that ITAS can be used at "crunch time" involved students desperately seeking tutor input into assessment tasks, reflects DEST's deficit model (DEST, 2005, A9.5.6), instead of perceiving ITAS 
tutorials as a capacity building relationship over the entire semester. This involves in-depth discussions between tutor and student on the content matter. For example, one tutor commented:

One major problem with time management: the simple formula of two-hours-per-unit-per-week adds significant time obligations to what can already be a very time-poor week for a student. It has been my experience that, for most, this amount of time can pose a stress capable of negating the original intent to provide assistance. Rather than attempt to provide tutoring in all of the units for a full-time load, it would seem to be more beneficial to cover the most problematic units but to leave at least one unit for the student to complete themselves. This reduces the time commitment of face-to-face meetings, and also enables the student to assess for themselves the benefit of tutorial assistance, thereby returning a degree of determination to the student. The fundamentals of scholarship afforded overall by tutorial contact are sufficient assistance to the student for constructing a personal frame or method of learning. Insisting on a one-size-fits-all formula risks extra stress and can detract from the agency of the student in their own advancement (ITAS Tutor \# 7).

Such reflections correlate with concerns of past ITAS students. First, it reveals the complexities of the restrictions set by external agencies that may not necessarily appreciate the individual needs of students and tutors. Second, ITAS is "additional tuition", thus adding pressure to "time poor" students to keep their commitments to attend scheduled classes as well as attending ITAS sessions. Most students are also allocating hours for ITAS while balancing these with work. It can be argued then that such commitments can make an impact on attendance at ITAS tutorial sessions, an issue which continues to be evidenced by high rates of "no shows" (cancellations) to ITAS sessions. Indeed, within the current arrangements, and as noted by the tutor and students above, insisting on a one-size-fits-all formula (maximum of two hours per week per subject) can likely reduce the prioritisation by students of meeting their ITAS commitments.

Employment of ITAS tutors is always on a part-time basis. While the Oodgeroo Unit has been quite fortunate to engage experienced tutors in a variety of disciplines, the turn-over of staff is high on an annual basis due to the high numbers of postgraduates and casual staff members who are always moving out of the university system or seeking full time employment. Much time is expended on recruiting appropriate tutors, replacing those who have moved on for reasons including the insecurity of the position, which is directly linked to the inflexibility of ITAS regulations (such as "losing" two hours work/income per subject when students cancel their sessions). Consequently, tutors tend to take on more regular work to ensure regular income, thereby having too many other commitments in addition to ITAS tutorial responsibilities, thus, less flexibility in time and place of ITAS tuition to meet the learning needs of the student. What appears to be the norm is that tutors who can commit to long-term ITAS tutorial employment are often retired professionals, which can require professional development not allowed for by DEST (that is, beyond the once-off two hours of cultural awareness training). This may include issues to do with recent developments in knowledge of disciplines and advancement of information technological systems. Gaps in tutors' knowledge and other issues such as cultural insensitivities have the potential to undermine student success in their studies.

\section{Student/tutor relationships}

Effective teaching and learning is dependent upon the power relationships that occur between tutors and students over a range of issues. Tutors found their involvement with ITAS contributed to improving their knowledge base, clarifying understanding within their own field of expertise, and enhancing their pedagogies. Contributing to students' successful completion of their studies was both professionally and personally rewarding. A substantial number of tutors commented on how much they valued the relationships they had formed with students. They described a sense of achievement in seeing students develop both personally and academically. This engagement enhanced their sense of social justice, and their recognition of, and contribution to, Indigenous equality through education. For example:

As a justice and human rights theorist I have particularly enjoyed exploring aspects of the relationship between white and [I]ndigenous Australia[ns] with my students. I have come to know that I understand a lot less about [I]ndigenous perspectives than I had once thought. I enjoy the one-on-one teaching much more than I do class teaching and I thoroughly enjoy the teaching and learning relationships I've been able to develop with students (ITAS Tutor \# 3).

Additionally, tutors reported that the insights they gained from participating in ITAS tuition arrangements contributed positively to their pedagogical practice outside of ITAS:

I have found it personally beneficial to clarify my own understanding and knowledge within my field of education by interacting [with] and assisting Indigenous students. Through this work 
I can continue to reflect on my own practice, beliefs and knowledge while also assisting others in a meaningful and worthwhile way (ITAS Tutor \#2).

Working in the ITAS program gave tutors the opportunity to become more culturally aware and to have a greater understanding of Indigenous perspectives:

Working with Aboriginal people is far more educational than trying to learn about issues through the veil of ignorance that is provided by the media. I thank the management for adding expansively to my understanding of both Indigenous culture and also culture as a general concept, and for the insights into understanding both difference and sameness (ITAS Tutor \#7).

Participation in the ITAS program also contributed significantly to the tutors' sense of professional accomplishment when they were privy to the success of students either through good results or gaining employment upon graduation:

The aspect of ITAS that I've found professionally rewarding is the opportunity to support students to achieve life and study goals. Each student is different in their abilities and commitment to study and it is a unique experience to be able to work with individuals (ITAS Tutor \# 12).

\section{Understanding student "success"}

A significant finding from this project is the broader definitions of success used by various tutors and students. Achieving a good grade was only one of a variety of indicators of success - seeing changes to students' life skills, achieving study goals (regardless of grade), attaining positions of power and influence, or desirable employment upon graduation were echoed in our findings. Herbert (2005, p. 14) found similar student understandings of success, in that the development of life skills may be seen as more important than their grade point average (GPA). She noted that DEST perceptions of success, however, were aligned with academic outcomes and course completions, reflecting strong linkages to Federal Government economic policy (2005, p. 14). Paradoxically though, DEST does not require education providers to compile graduate destinations against ITAS provision, and the administrative procedures inherent in the current paper based system do not systematically capture these potential indicators of success.

Another "successful" outcome of ITAS not currently measured is the contribution to the cultural awareness of the tutors and the consequences of their improved knowledge base in other teaching and learning settings. QUT has embarked on a series of projects to embed Indigenous perspectives (McLaughlin \& Whatman, 2007) which has contributed to a growing awareness of the benefit to all Australians, not only Indigenous Australians, of Indigenous knowledge and Indigenous perspectives (Phillips, 2005). ITAS is yet another pathway for respect for Indigenous knowledge and perspectives to increase and be recognised in academia. This correlates with Herbert's (2005, pp. 10-11) findings that students regard such an "enabling" exchange as not only a way of becoming empowered themselves, but also as a way of enhancing the reconciliation process within universities. This outcome is as important to students as their own empowerment, because of the potential for societal change (Herbert, 2005, p. 11).

\section{Conclusion and implications for future work}

Our analysis of ITAS at one university echoes sentiments that surely it is time to move on with theorising in Indigenous education, from the misconception of Indigenous learners as deficient, to a richer, more empowering understanding of Indigenous university students as successful learners despite the challenges posed by the university system (Nicholls et al., 1996). By investigating how we did (and potentially could) administer, monitor and assess the quality of teaching through ITAS, how we used this information, and what were the successful outcomes for stakeholders of the quality of teaching and learning enabled through ITAS, we believe we have made a small but significant contribution to this highly specialised field of literature. Identifying and explaining the relationships and consequences of factors upon Indigenous student success allows us and similar centres around Australia, to modernise and enhance the effectiveness of this support strategy.

Our findings at this early stage of the project confirm what has been suggested in earlier publications (Morgan, 2003; Oodgeroo Unit, 2003) about the burden of administration that is placed upon institutions that offer ITAS. New guidelines which still emphasise the reporting of statistical outcomes and financial acquittal over and above the quality of teaching and learning outcomes have translated into onerous trails of paperwork, the labour for which is not fully reimbursed by DEST, and results in serious impediments to Oodgeroo Unit employees' abilities to meet their other career obligations. Clearly, the ongoing consequences for staff who continue to offer ITAS under these conditions require further critique which would illuminate impediments to the quality of teaching and learning in ITAS in the future.

The misconception of Indigenous student "deficiency" has been exposed in our research, as QUT students enjoy high participation and completion rates against the national average, yet only $25 \%$ use ITAS. 
Our students are clearly not deficient, so exposing current expectations and operations of ITAS and thus rethinking the ways in which ITAS could appeal to already competent learners, producing even better outcomes, would contribute to better understandings of "success". The potential for ITAS administrative processes and operations to capture quality data on student success have been hampered by the inflexibility of DEST requirements. Thus, the changes to our processes are confined, but still possible under these requirements, by moving ITAS into a virtual environment (Beetson et al., 2007).

The definition of "success" of all Aboriginal and Torres Strait Islander students at university, including those who do not access ITAS, still requires much further exploration, particularly from the students perspectives (Herbert, 2005). Students may not use ITAS as "some may see it as an admission of failure to avail themselves of it" (Morgan, 2003, p. 10). This study has clearly uncovered correlations between the restrictive nature of the funding guidelines and the nature of the teaching and learning relationship that is possible between tutors and students. More investigation is required into this issue.

With continual changes to the guidelines and funding criteria, staff members who administer the program need to create enduring systems of administration and quality assurance. This comprises two interrelated aspects. First, a critical curriculum design to ITAS, based upon dynamic involvement of all stakeholders (tutors, students, academic advisors and professional staff) beyond the minimum requirements for work programs. Second, a data management system that not only captures the minimum quantitative and qualitative data requirements for reporting to DEST, but can actually inform the kinds of changes that we have indicated may be required from this study. The system design must capture and contain quality data and additional knowledge that can be used internally to inform the practice of all stakeholders. For example, tutors indicated a need for greater understanding of cultural awareness - our ITAS system could provide this knowledge in a dynamic forum with instant access, without waiting for a "once a year" cultural awareness training session. DEST rules prevent tutors from being paid to attend more than one session, yet this implies cultural awareness is a knowledge set that can be completely acquired and understood in two hours. The consequences of restrictions such as these can be countered with strategic development of ITAS management systems and ongoing lobbying to review and revise ITAS reporting requirements to overcome the issues we have attributed to their current inflexibility. The QUT Oodgeroo Unit are progressing this argument with the development of a prototype ITAS management system that operates in a virtual environment (see www.oodgeroo.qut.edu.au/ academicpapers/ITAS/). The detail of this prototype is beyond the scope of this paper and will be published in due course.

\section{References}

AIATSIS. (2000). Guidelines for ethical research in Indigenous studies May 2000. Retrieved 1 July, 2007, from http://www.aiatsis.gov.au/data/assets/ pdf_file/2290/ethics_guidelines.pdf.

Bassey, M. C. (1999). Case study research in educational setting. Buckingham: Open University Press.

Beetson, S., Tyhuis, A., Willsteed, S., McLaughlin, J., \& Whatman, S. (2007, July). Bringing ITAS into a virtual environment. Paper presented at the Indigenous Studies and Indigenous Knowledge Conference, Sydney, New South Wales, Australia. Retrieved 1 August, 2007, from http://www. oodgeroo.qut.edu.au/academic_resources/academicpape/itas/index.jsp.

Bin-Sallik, M. A. (1991). Aboriginal tertiary education in Australia: How well is it serving the needs of Aborigines? Underdale, SA: Aboriginal Studies Key Centre.

Boulton-Lewis, G., Marton, F., Lewis, D.C., \& Wilss, L.A. (2000). Learning in formal and informal contexts: conceptions and strategies of Aboriginal and Torres Strait Islander university students. Learning and Instruction, 10(5), 393-414.

Brady, W. (1992). Beam me up Scotty, communicating across world views on knowledge, principles and procedures for the conduct of Aboriginal and Torres Strait Islander research. In C. White (Ed.), National Aboriginal and Torres Strait Islander Higher Education Conference proceedings (pp. 104115). Toowoomba, QLD: University of Southern Queensland.

Carpenter, B., Field, R., \& Barnes, M. (2002). Embedding Indigenous content and perspectives across the justice studies curriculum: Developing a cooperative integrated strategy. Paper presented at the Australian Association for Research in Education Conference, Melbourne, Victoria, Australia. Retrieved 1 July, 2007, from http:/www.aare.edu.au/02pap/ car02109.htm.

DEET. (1989). National Aboriginal education policy. Canberra, ACT: Australian Government Publishing Service.

DEST. (2002). National Report to Parliament on Indigenous Education and Training. Retrieved 21 June, 2007, from http://www.dest.gov.au/NR/ rdonlyres/349C26F1-1E97-4370-9C4C-53A17DA11D/1147/7.rtf.

Donovan, R. J., \& Spark, R. (1997). Towards guidelines for survey research in remote Aboriginal communities. Australian and New Zealand Journal of Public Health, 21(1), 89-95.

Fredericks, B. (2007). Utilising the concept of a pathway as a framework for Indigenous research. Australian Journal of Indigenous Education, 36 (S), 14-21.

Harrison, N. (2005). The learning is in-between: The search for a metalanguage in Indigenous education. Educational Philosophy and Theory, 37(6), 871-884.

Hart, V., \& Whatman, S. (1998, July). Decolonising the concept of knowledge. Proceedings of the Higher Education, Research and Development Society of Australasia International Conference, Auckland, New Zealand. Retrieved 1 July, 2007, from http://www.oodgeroo.qut.edu.au/academic_resources/ academicpape/decolonising.jsp.

Herbert, J. (2003, November-December). Indigenous research - A communal act. Paper presented at the International Education Research Conference AARE-NZARE, Auckland, New Zealand. Retrieved 1 July, 2007, from http://www.aare.edu.au/03pap/her03635.pdf. 
Herbert, J. (2005, July). Owning the discourse: Seizing the power! Paper presented at Education Research: Creative Dissent: Constructive Solutions AARE 2005 Conference, Cairns, Australia. Retrieved 1 July, 2007, from http://www.aare.edu.au/05pap/her05217.pdf.

Houston, J. (2007). Indigenous authoethnography: Formulating our knowledge, our way. Australian Journal of Indigenous Studies, 36(S), 45-50.

Huggins, J. (1998). Sister girl: The writings of Aboriginal activist and historian Jackie Huggins. St Lucia, QLD: University of Queensland Press.

IHEAC. (2006). Improving Indigenous Outcomes and Enhancing Indigenous Culture and Knowledge in Australian Higher Education: Strategic Plan of the Indigenous Higher Education Advisory Council 2006-2008. Retrieved 1 July, 2007, from, http://www.dest.gov.au/sectors/indigenous_education/ publications_resources/profiles/improving_indig_outcomes.htm.

LeCompte, M. D., \& Preissle, J. (1993). Ethnography and qualitative design in educational research (2nd ed.). San Diego, CA: Academic Press.

Macpherson, I., \& Aspland, T. (2001). BEd reconceptualisation. Brisbane, QLD: Queensland University of Technology.

Martin, K. (2001, September). Ways of knowing, ways of being and ways of doing: Developing a theoretical framework and methods for Indigenous re-search and Indigenist research. Presented at the AIATSIS Indigenous Studies Conference, Canberra, Australia. Retrieved 1 July, 2007, from http://www.aiatsis.gov.au/__data/assets/pdf_file/5718/MARTIN.pdf .

McLaughlin, J. (2006). QUT Oodgeroo Unit centralised assessment and selection program (CASP) report. Brisbane, QLD: Queensland University of Technology.

McLaughlin, J., \& Whatman, S. (2007, July). Embedding Indigenous perspectives in university teaching and learning. Paper presented at the Indigenous Education Conference, First Nations University, Vancouver, Canada.

Mellor, S., \& Corrigan, M. (2004). The case for change: A review of contemporary research on Indigenous education outcomes. Camberwell, VIC: Australian Council for Educational Research Press.

Moreton-Robinson, A. (2000). Troubling business: Difference and whiteness within feminism. Australian Feminist Studies, 15(33), 343-352.

Moreton-Robinson, A. (Ed.). (2004). Whitening race: Essays in social and cultural criticism. Canberra, ACT: Aboriginal Studies Press.

Morgan, D. L. (2003). NIPAAC response to review of the ATAS bulk-funding arrangements under the Indigenous Education Direct Assistance Programme, Canberra, DEST. Retrieved 1 July, 2007, from http://www.nipaac.edu.au.

Nakata, M. (1993) Culture in education: For us or for them? In N. Loos \& T. Osanai (Eds.), Indigenous minorities and education: Australian and Japanese perspectives of their indigenous peoples, the Ainu, Aborigines and Torres Strait Islanders (pp. 334-349). Tokyo: Sanyusha.

Nakata, M. (1999). Multiliteracies and Indigenous standpoints. Australian Language Matters, 7(4), pp. 113-120.

Nakata, M. (2001). Another window on reality. In B. Osborne (Ed.), Teaching, democracy and diversity (pp. 331-353). Altona, VIC: Common Ground Publishing.

Nash, R. (2004). Towards cultural competence: An innovative strategy for incorporating Aboriginal and Torres Strait Islander perspectives within health professional curricula, Queensland University of Technology. Retrieved 1 July, 2007, from http://www.talss.qut.edu.au/staff/grants/qut_ grants/projects_year/project_doc/2004/2004_1_04.jsp.
NHMRC. (2003). Values and ethics: Guidelines for ethical conduct in Aboriginal and Torres Strait Islander health research. Retrieved 1 July, 2007, from http://www.nhmrc.gov.au/publications/synopses/e52syn.htm.

Nicholls, C., Crowley, V., \& Watt, R. (1996). Theorising Aboriginal education: Surely it's time to move on? Education Australia, 33, 6-9.

Oodgeroo Unit. (2000). Review of the Oodgeroo Unit. Brisbane, QLD: Queensland University of Technology.

Oodgeroo Unit. (2003). Response to the DEST review of bulk funding arrangements. Brisbane, QLD: Queensland University of Technology.

Oodgeroo Unit. (2005). ITAS program report: April 2005. Unpublished report to the Department of Education, Science and Training. Brisbane, QLD: Queensland University of Technology.

Phillips, J. (2005). Indigenous knowledge: Making space in the Australian centre. In J. Phillips \& J. Lampert (Eds.), Introductory Indigenous studies in education: The importance of knowing (pp. 2-10). Frenchs Forest, NSW: Pearson Education Australia.

Phillips, J., \& Lampert, J. (Eds.), Introductory Indigenous studies in education: The importance of knowing. Frenchs Forest, NSW: Pearson Education Australia.

Rigney, L. I. (1997). Internationalisation of an Indigenous anti-colonial cultural critique of research methodologies: A guide to Indigenist research methodology and its principles. Journal for Native American Studies, 14(2), $109-125$.

Shnukal, A. (2002). Some language-related observations for teachers in Torres Strait and Cape York Peninsula schools. Australian Journal of Indigenous Education, 30(1), 8-24.

Smith, L. T. (1999). Decolonising methodologies: Research and Indigenous peoples. Dunedin, New Zealand: University of Otago Press.

Stake, R. E. (1995). The art of case study research. Thousand Oaks, CA: Sage Publications.

Stewart, J. (2007). Grounded theory and focus group: Reconciling methodologies in Indigenous Australian education research. Australian Journal of Indigenous Education, 36 (S), 31-36.

Taylor, P. (2002). Doing it differently: Link and learn - The work of the Indigenous Education and Training Alliance. Australian Journal of Indigenous Education, 30(1), 43-52.

Tripcony, P. (2001). The Commonwealth Referendum of 1967 and Australian Indigenous citizenship: An interpretation of historical events. Journal of Indigenous Issues, 4(2), 26-33.

Walker, P. (2003). Colonising research: Academia's structural violence towards indigenous peoples. Social Alternatives, 22(3), 37-40.

Watts, B. H. (1982). Aboriginal futures: A review of research and developments and related policies in the education of Aborigines. Canberra, ACT: Australian Government Publishing Service.

Weber-Pillwax, C. (2001). What is Indigenous research? Canadian Journal of Native Education, 25 (2), 166-176.

Williamson, J., \& Dalal, P. (2007). Indigenising the curriculum or negotiating the tensions at the cultural interface? Australian Journal of Indigenous Education, 36 (S), 51-58.

Williamson, J., \& Towers, S. (2004). Developing and enhancing Indigenous perspectives in the curriculum: An initiative of QUT (Carseldine and Creative Industries Final Report). Retrieved 1 July, 2007, from http://www. talss.qut.edu.au/staff/grants/qut_grants/projects_year/FinRpt_SG_2002_ WilliamsonTowers.doc. 
About the authors

Sue Whatman is a non-Indigenous Lecturer who was born in Murwillumbah, Minjungbal country, in far northern NSW, and is a graduate of QUT. Sue completed her doctoral studies in 2004. She is currently the Liaison Lecturer for Indigenous students enrolled in the Faculty of Creative Industries and she teaches Indigenous Studies in the Education Faculty at the Carseldine Campus of QUT. With a health and physical education teaching background, Sue has an active research interest in health education for Indigenous girls and a strong commitment to incorporating Aboriginal and Torres Strait Islander perspectives, content and pedagogies into QUT courses.

Juliana McLaughlin is from Manus Island in Papua New Guinea. Juliana completed her PhD at QUT in 2002. Before working in the Oodgeroo Unit at Queensland University of Technology, she worked as a research assistant and sessional academic in the Faculty of Education. Her research interests are driven by a commitment and responsibility to Indigenous knowledge systems, decolonising methodologies and embedding Indigenous ways of knowing in university programs.

Susan Willsteed is non-Indigenous and was born and grew up in Turrubal country (Brisbane's north side), and is a graduate of QUT. Susan has an early childhood teaching background. She has for many years been involved in supporting Indigenous students at all levels of education, and in advocating for the incorporation of Aboriginal and Torres Strait Islander perspectives at all levels of education and within the wider community. She currently teaches Indigenous Studies in the Education and Humanities Faculties at QUT, and is the Academic Advisor for Indigenous students enrolled in the Faculty of Education.

Annie Tyhuis is a Torres Strait Islander, originally from Darnley Island, Eastern Torres Strait. She works at the Oodgeroo Unit at Queensland University of Technology and enjoys interacting with the Indigenous and non-Indigenous students and staff at QUT. She also participated in a recent publication, Introductory Indigenous studies in education: The importance of knowing (edited by Jean Phillips and Jo Lampert).

Susan Beetson is a Murri woman of the Weilwan Clan of the Ngemba language group and spent her early years growing up in Brewarrina. She has worked in Information Technology for over 16 years. With a Bachelor of Information Technology Susan is currently completing an Information Technology Research Honours degree. Susan is an Associate Lecturer with the Oodgeroo Unit at Queensland University of Technology (QUT) and teaches both in the Humanities and Faculty of Information Technology. 

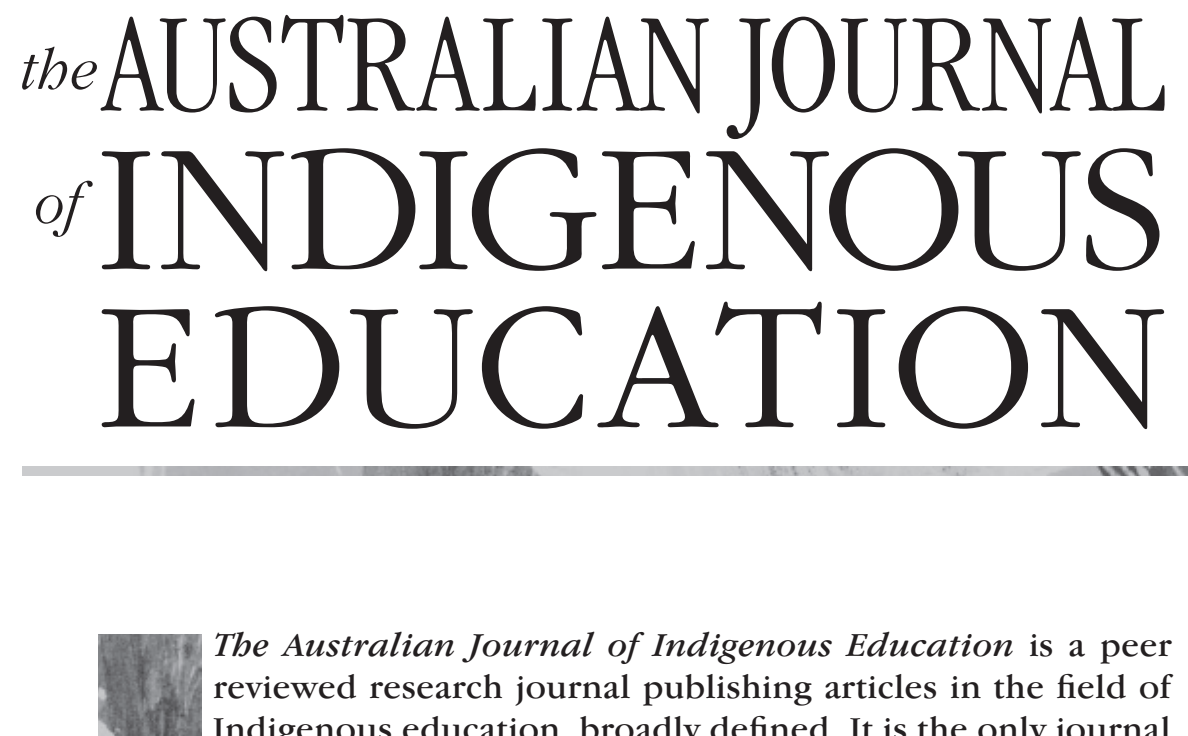

The Australian Journal of Indigenous Education is a peer reviewed research journal publishing articles in the field of

Indigenous education, broadly defined. It is the only journal for educators devoted specifically to issues of practice, pedagogy and policy in Indigenous education in Australia. The journal has an international audience and is highly valued by its readers as a reliable source of information on Indigenous education issues Contributions on the participation of Indigenous people in education and training; equitable and appropriate access and achievement of Indigenous people in education and training; and the teaching of Indigenous studies, cultures and languages to both Indigenous and non-Indigenous students are encouraged. Notes to Contributors can be found at the back of each issue. The journal is published by the Aboriginal and Torres Strait Islander Studies Unit at the University of Queensland, under the strategic management and with the support of the Unit Director, Michael Williams.

Editors: Jackie Huggins \& Elizabeth Mackinlay

Managing Editor: Sean Ulm

Acting Managing Editor: Katelyn Barney

Book Review Editor: Sean Ulm

Acting Book Review Editor: Katelyn Barney

Administrative Assistant: Jan Stewart

Graphic Design: Lovehate Design

Printing: Screen Offset Printing

Artwork: Adapted from Jungle Vine (2002)

by Macsen Ja-wukanyi Chalmers

and Knowledge Network (2005)

by Robert Stuurman

All correspondence and submissions should be addressed to:

The Editors

The Australian Journal of Indigenous Education

Aboriginal and Torres Strait Islander Studies Unit

The University of Queensland

Brisbane QLD 4072

AUSTRALIA

Email: ajie@uq.edu.au

URL: http://www.atsis.uq.edu.au/ajie/

1. The views expressed in this journal are not necessarily those of the Editors or Publisher.

(C) Aboriginal and Torres Strait Islander Studies Unit

The University of Queensland, 2008

ISSN 1326-0111

ISBN 9781864999242 


\section{TABLE of CONTENTS}

EDITORIAL

INTRODUCTION

Martin Nakata

INDIGENOUS KNOWLEDGE STUDIES and the NEXT GENERATION: PEDAGOGICAL POSSIBILITES for ANTI-COLONIAL EDUCATION

George J. Sefa Dei

INDIGENOUS KNOWLEDGE \& INTELLECTUAL PROPERTY: NEGOTIATING the SPACES

Terri Janke

INDIGENOUS KNOWLEDGE: BEYOND PROTECTION, TOWARDS DIALOGUE

Michael Davis

UNIVERSITIES as the GATEKEEPERS of the INTELLECTUAL PROPERTY of INDIGENOUS PEOPLE'S MEDICAL KNOWLEDGE

Chris Kavelin

INDIGENOUS KNOWLEDGE and the CONVENTION on BIOLOGICAL DIVERSITY

Robynne Quiggin

FINDING HYBRID SOLUTIONS to the FINANCIAL MANAGEMENT of CUSTOMARY LAND

from a PACIFIC PERSPECTIVE

Spike Boydell

'JAPAN FIGHT. ABORIGINAL PEOPLE FIGHT. EUROPEAN PEOPLE FIGHT': YOLNGU STORIES from WORLD WAR II

Noah Riseman

JUST PUSH PLAY: WHERE RESEARCH MEETS VIDEO, ONLINE

Jason De Santolo \& Juanita Ypinazar

The NEED to EXTEND BEYOND the KNOWLEDGE GAINED in CROSS-CULTURAL AWARENESS TRAINING

Bronwyn Fredericks

LINKING LEARNING to COMMUNITY for INDIGENOUS COMPUTING COURSES

Cat Kutay \& Janet Mooney

INDIGENOUS EPISTEMOLOGIES in TERTIARY EDUCATION

Shane Edwards \& Kieran Hewitson

AUSTRALIAN UNIVERSITY APPROACHES to INDIGENOUS POLICY

Andrew Gunstone

BENEATH the TEACHING ICEBERG: EXPOSING the HIDDEN SUPPORT DIMENSIONS

of INDIGENOUS ACADEMIC WORK

Susan Page \& Christine Asmar 
QUALITY and EFFICACY of the INDIGENOUS TUTORIAL ASSISTANCE SCHEME (ITAS) for UNIVERSITY STUDENTS

Sue Whatman, Juliana McLaughlin, Susan Willsteed, Annie Tyhuis \& Susan Beetson

CRITICAL REFLECTIONS on the CENTRAL ROLE of INDIGENOUS PROGRAM FACILITATORS in EDUCATION for SOCIAL CHANGE

Sonya Pearce

APPROACHES to the ACADEMIC PREPARATION and SUPPORT of AUSTRALIAN INDIGENOUS STUDENTS for TERTIARY STUDIES

Martin Nakata,Vicky Nakata \& Michael Chin

INDIGENOUS PEDAGOGY as a FORCE for CHANGE

Soenke Biermann \& Marcelle Townsend-Cross

NOTES to CONTRIBUTORS 